\title{
INVENTÁRIO E DIAGNÓSTICO DA ARBORIZAÇÃO EM QUATRO ÁREAS PÚBLICAS NA CIDADE DE GUAÇUÍ - ES
}

\author{
INVENTORY AND AFFORESTATION DIAGNOSIS IN FOUR PUBLIC AREAS IN \\ GUAÇUI CITY (ESPIRITO SANTO STATE, BRAZIL)
}

\author{
Lucas Duarte Caldas da Silva ${ }^{1}$, Rafael Marian Callegaro², Kelen Pureza Soares ${ }^{3}$, \\ José Renato Azedias Campos ${ }^{4}$, Filipe Meneguelli 5
}

\section{RESUMO}

Esta pesquisa teve como objetivo realizar um diagnóstico da arborização em quatro praças da cidade de Guaçuí - ES. Foi realizado o censo quali-quantitativo dos indivíduos com diâmetro à altura do peito $(\mathrm{DAP}) \geq 5,0 \mathrm{~cm}$. Constatou-se que Poincianella pluviosa (DC.) L.P.Queiroz foi a única com frequência $(31,9 \%)$ superior a recomendada. As famílias Arecaceae (30 indivíduos; nove espécies) e Fabaceae (48 indivíduos; sete espécies) tiveram maior riqueza e abundância. O número de espécies exóticas (22) foi superior ao número de nativas (nove), indicando a necessidade de implantação de mais espécies nativas. A qualidade geral da arborização urbana foi satisfatória, embora sejam necessários manejos específicos em alguns locais. A área circundante à Prefeitura teve as piores condições de fitossanidade (ruim: $16,7 \%$ ) e do sistema radicular, com $20,0 \%$ das árvores causando danos moderados ou severos ao piso. Na Praça Vicente Camuzi a maior demanda por alguma forma de poda $(57,1 \%)$ e na Praça João Acacinho encontrou-se a maior proporção de árvores com qualidade de copa ruim (12,2\%). Os índices de sombreamento arbóreo foram satisfatórios, mas os índices de densidade arbórea foram inferiores aos recomendados. Infere-se que a arborização das áreas públicas pesquisadas teve boas características quali-quantitativas, mas necessita de algumas intervenções.

Palavras-chave: Avaliação quali-quantitativa; Área verde; Qualidade ambiental; Árvores urbanas.

\begin{abstract}
Urban trees in Guaçuí city squares were qualitative and quantitatively analyzed by a census of trees with diameter at breast height $\geq 5.0 \mathrm{~cm}$. The Poincianella pluviosa (DC.) L.P.Queiroz (37 individuals) was the only species with higher frequency than recommended. Arecaceae (30 individuals, nine species) and Fabaceae (48 individuals, seven species) were the families with the greatest richness and abundance. The exotic species number (22) was higher than native species number (nine), indicating that there is a need of native species appreciation. The overall tree quality in the four wooded areas was satisfactory, although there are specific management problems in some places. The area next to Town Hall had the worst phytosanitary conditions (bad: $16.7 \%$ ) and the root system conditions, with $20.0 \%$ of the trees causing moderate or severe damage. The João Acacinho Square contained the higher trees proportion with a poor crown quality (12.2\%) and Vicente Camuzi Square had the highest demand for some form of pruning $(57.1 \%)$. The arboreal shade indexes were satisfactory, but all of them had lower tree density indices than those recommended. It is concluded that the afforestation of the public areas surveyed had good qualitative-quantitative characteristics, but it needs interventions to improve the environmental quality provided to the population.
\end{abstract}

Keywords: Quali-quantitative evaluation; Green area; Environmental quality; Urban tree.

Recebido em 14.03.2017 e aceito em 07.07.2017

1 Graduando em Engenharia Florestal. Universidade Federal do Espírito Santo (UFES). Jerônimo Monteiro/ES. Email: lukedcds@gmail.com

2 Engenheiro Florestal. Doutor. Professor Adjunto da UFES. Jerônimo Monteiro/ES. Email: rafaelm.callegaro@gmail.com

3 Engenheiro Florestal. Mestre. Pindorama Consultoria Ambiental Ltda. Belo Horizonte/MG. Email: kpsoares@gmail.com

4 Graduando em Engenharia Florestal. UFES. Jerônimo Monteiro/ES. Email: joserenatoazedias@hotmail.com

5 Graduando em Engenharia Florestal. UFES. Jerônimo Monteiro/ES. Email: filipe.meneguelli@hotmail.com 


\section{INTRODUÇÃO}

A arborização urbana pode ter características específicas em cada cidade, devido, por exemplo, a implantação embasada ou não por um planejamento. Nesse sentido, considera-se que o planejamento adequado da arborização é um pressuposto para que seus benefícios sejam expressos e, conforme Oliveira et al. (2017), é essencial para que a arborização cumpra o seu papel a curto, médio e longo prazo.

Entre os benefícios da arborização urbana, destaca-se a melhoria na qualidade de vida da população, a qual pode ser promovida pela utilização de espécies com atributos estéticos e/ou funcionais. A implantação de espécies com fins estéticos pode diminuir a poluição visual nas cidades, bem como criar áreas visualmente mais agradáveis em contraste às construções urbanas. Quanto aos aspectos funcionais, a melhora no conforto térmico e a possibilidade de diminuição de poluição atmosférica e sonora, entre outros, são benefícios futuros que justificam a implantação e o manejo adequado de árvores nas cidades.

Considerando a arborização urbana, a obtenção dos seus benefícios está diretamente ligada à qualidade, podendo estes benefícios serem maximizados através de sugestões resultantes do seu diagnóstico (SILVA, 2003). Assim, o diagnóstico surge como ferramenta importante, fornecendo informações para avaliar a situação da arborização e identificar os possíveis problemas que precisam ser solucionados, contribuindo para o replanejamento de determinadas áreas e o planejamento de outras (FARIA et al., 2013; OLIVEIRA et al., 2017).

Devido à importância das árvores na área urbana e a necessidade de estudos que forneçam informações sobre os seus componentes e subsidiem a gestão de áreas arborizadas, esta pesquisa teve como objetivo realizar um diagnóstico da arborização em quatro praças da cidade de Guaçuí - ES.

\section{MATERIAL E MÉTODOS}

O município de Guaçuí está localizado a 2046'34" de latitude Sul e $41^{\circ} 40^{\prime \prime} 33^{\prime \prime}$ de longitude Oeste, na região serrana do sul do Estado do Espírito Santo, e tem área total de $468,343 \mathrm{~km}^{2}$. Seu território é acidentado com montanhas, vales e rios, onde a altitude varia de 600 a 1400 m. O clima, segundo a classificação de Köppen, é Cfa, subtropical com verão quente (ALVARES et al., 2013). A pluviosidade média anual é de $1246 \mathrm{~mm}$ e a temperatura média anual de $19,1^{\circ} \mathrm{C}$ (FLORES et al., 2016). A população no ano de 2010 era de 27.851 habitantes, com densidade demográfica de 59,47 habitantes por $\mathrm{km}^{2}$ e índice de desenvolvimento humano municipal de 0,703 (IBGE, 2017) (Figura 1). 


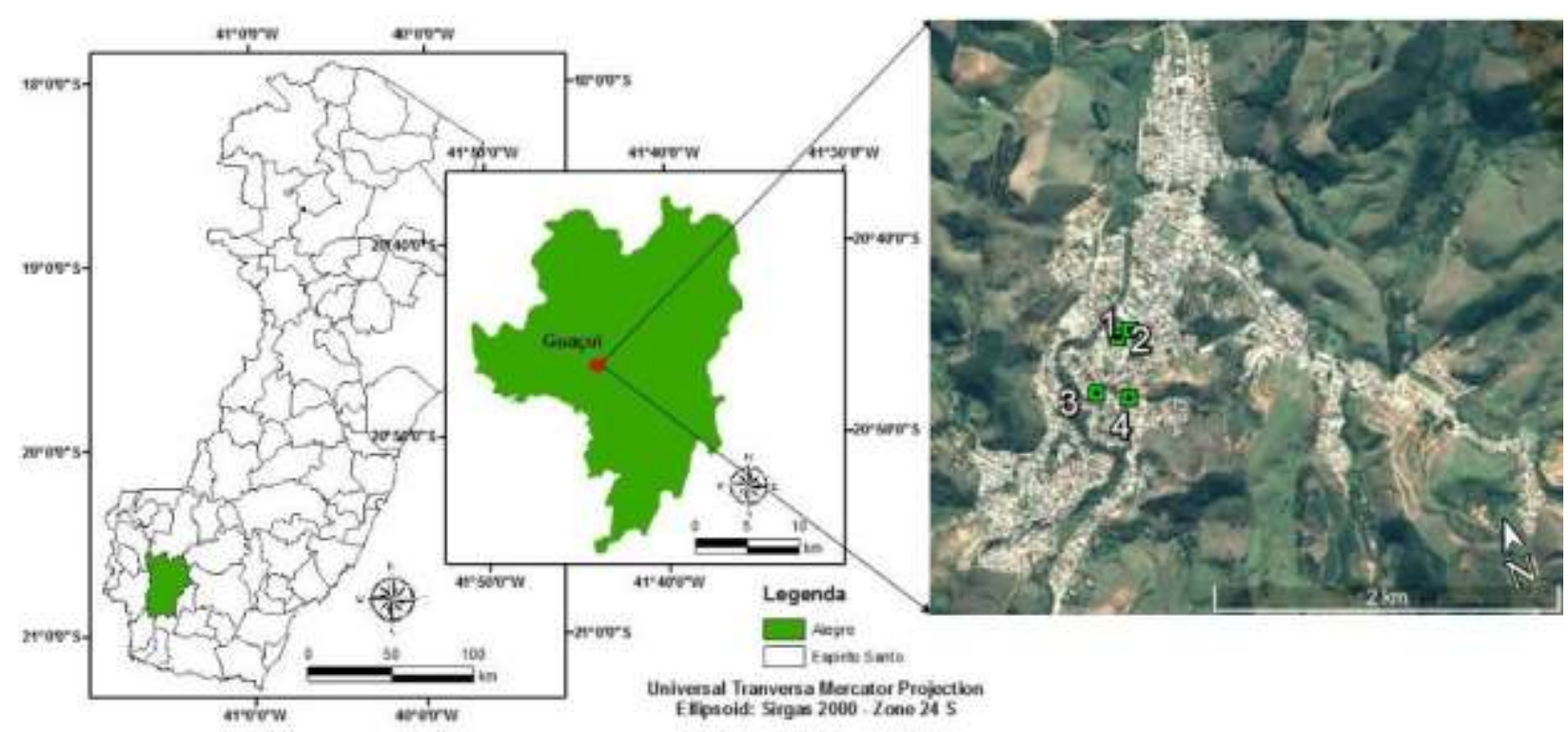

1: Área pública da Prefeitura; 2: Praça João Acacinho; 3: Praça da Matriz; 4: Praça Vicente Camuzi.

Figura 1. Localização geográfica das praças na cidade de Guaçuí, Espírito Santo

Figure 1. Geographical location of squares in the Guaçuí city, Espírito Santo State

Foi avaliada a arborização de quatro áreas públicas da cidade de Guaçuí: Praça João Acacinho, Praça da Matriz, Praça Vicente Camuzi e a área verde circundante a Prefeitura. A Praça João Acacinho tinha a maior quantidade de equipamentos urbanos, incluindo brinquedos para recreação de crianças, academia ao ar livre, bancos para descanso e quiosques com mesas e bancos, além de dois pontos de venda de lanche anexos à Praça. Essas características expõe a recreação e o descanso como os principais usos desta área pública. $\mathrm{A}$ Praça da Matriz continha bancos e monumento, sendo utilizada principalmente para o descanso, além de atividades promovidas pela Igreja localizada adjacente a Praça. Por outro lado, a Praça Vicente Camuzi possuía apenas um ponto de venda de lanches, tornando-se um local de recreação durante a abertura do estabelecimento. A área circundante ao prédio da Prefeitura possuía a arborização em passeios e áreas com gramado, sendo considerada um local público passível de uso, principalmente de passagem e breves descansos para pedestres. Essas áreas foram escolhidas por estarem localizadas na área central da cidade, possuírem diferenças quanto aos equipamentos urbanos e a priori quanto às características da arborização.

No período entre agosto e outubro de 2016, foi realizado o censo dos indivíduos arbóreos presentes nas quatro áreas públicas pesquisadas em Guaçuí - ES. Para obtenção dos dados de cada indivíduo arbóreo foi elaborada uma ficha de campo. A altura total e a altura da bifurcação foram medidas utilizando-se o Hipsômetro Eletrônico Haglof HEC-2. A circunferência à altura do peito (CAP) e o raio da copa foram respectivamente obtidos através de uma fita métrica e uma trena. 
O procedimento de inclusão dos indivíduos levou em conta o CAP $\geq 15,7 \mathrm{~cm}$ (diâmetro à altura do peito - DAP $\geq 5 \mathrm{~cm}$ ). A nomenclatura científica das espécies foi confirmada por buscas nos bancos de dados Flora do Brasil 2020 (FORZZA et al., 2017) e Tropicos® (MBG, 2017), sendo tais espécies incluídas em famílias botânicas reconhecidas pelo sistema Angiosperm Phylogeny Group IV (BYNG et al., 2016). Essas pesquisas também foram utilizadas para determinar a origem de cada espécie: nativa ou exótica. A riqueza de espécies consistiu na contabilização do número de espécies, enquanto a abundância se referiu ao número de indivíduos.

As informações qualitativas foram obtidas sempre pela mesma pessoa, adaptadas de Silva (2003) e Maranho e Paula (2014): fitossanidade (boa - indivíduo sem sinais de praga, doenças ou danos mecânicos; regular - indivíduo com pequenos problemas de pragas, doenças ou danos mecânicos; ruim - indivíduo em declínio ou com grandes danos causados por pragas, doenças ou injúrias mecânicas; e morta - indivíduo sem sinais de vida;); condição do sistema radicular (profundo e sem danos; superficial e sem danos; dano moderado - sistema radicular provocou poucas rachaduras ou leve elevação no piso; e dano severo - sistema radicular causou desnível significativo, destruindo o piso do passeio ou da rua), qualidade da copa (boa - inteira e bem distribuída; regular - levemente deformada, com ramos quebrados; ruim - muito deformada, com ausência pronunciada de galhos ou com poda drástica;). Quanto a poda, determinou-se a necessidade dos seguintes tipos de poda para cada indivíduo: limpeza; afastamento; liberação fiação; levantamento copa; e ausente - quando não havia necessidade de poda).

A análise dos índices de cobertura arbórea foi baseada em Lima Neto, Resende e Souza (2007), sendo calculados os índices de sombreamento arbóreo (ISA) (Equação 1) e de densidade arbórea (IDA) (Equação 2). Conforme as descrições dos autores, o ISA permite inferir sobre o potencial de sombreamento da arborização urbana em determinada área (relação entre a soma das áreas das copas e a área total do local avaliado), enquanto o IDA indica se a quantidade de árvores é adequada (número de árvores por $100 \mathrm{~m}^{2}$ ).

$$
\begin{gathered}
I S A=\left(\frac{\text { Área }_{\text {sombreada }}\left(m^{2}\right)}{\text { Área }_{\text {total }}\left(m^{2}\right)}\right) \times 100 \\
I D A=\left(\frac{N_{\text {árvores }}}{\text { Área }}\right) \times 100
\end{gathered}
$$

Onde: $I S A=$ índice de sombreamento arbóreo;

IDA= índice de densidade arbórea;

Área sombreada área sombreada pela projeção de todas as copas;

Área total = dimensão da área pública pesquisada;

$\mathrm{N}$ árvores = número de árvores. 


\section{RESULTADOS E DISCUSSÃO}

Foram amostrados 116 indivíduos, pertencentes a 32 espécies e 15 famílias botânicas, incluindo uma espécie indeterminada e um indivíduo identificado em nível de gênero. As famílias que mais contribuíram em número de espécies foram Arecaceae (9 espécies $=28,1 \%$ do total), Fabaceae ( 7 espécies $=21,9 \%$ ), Bignoniaceae ( 3 espécies=9,4\%) e Asparagaceae (2 espécies=6,3\%), sendo as demais famílias representadas por uma espécie cada. Notou-se que a maior parte da riqueza de espécies encontrada nas praças da cidade de Guaçuí-ES pertence às famílias Arecaceae e Fabaceae (50,0\% total). As famílias Fabaceae com 48 indivíduos $(41,4 \%)$ e Arecaceae com 30 indivíduos (25,9\%) tiveram as maiores abundâncias. Resultados similares foram encontrados na arborização de áreas públicas em diferentes regiões do Brasil, por exemplo, pelas pesquisas de Schallenberger et al. (2010) em parques e praças de Irati - PR (Fabaceae: sete espécies; Arecaceae: duas espécies), Teixeira et al. (2016) na Praça Camilo Mércio em São Gabriel - RS (Fabaceae: seis; Arecaceae: cinco) e Tischer, Forte e Pedroso-de-Moraes (2014) em praças da cidade de Leme - SP (Fabaceae: 11; Arecaceae: cinco), onde as famílias Fabaceae ou Arecaceae tiveram elevado número de espécies implantadas nos referidos espaços urbanos em relação às demais famílias observadas (Tabela 1).

Em termos de abundância de indivíduos (frequência), verificou-se que as cinco principais espécies (Dypsis lutescens ( $\mathrm{H}$. Wendl.) Beentje \& J. Dransf. (areca-bambu), Licania tomentosa (Benth.) Fritsch (oiti), Poincianella pluviosa (DC.) L.P.Queiroz (sibipiruna), Roystonea borinquena O.F. Cook (palmeira-coca-cola) e Syagrus romanzoffiana (Cham.) Glassman (jerivá)) representaram $62,1 \%$ do total de indivíduos registrados no censo. Estas espécies foram encontradas na arborização de outras cidades brasileiras, por exemplo, em Lavras-MG (ALVES; CARVALHO, 2010), Águas de São Pedro-SP (BORTOLETO et al., 2007), Goiandira-GO (PIRES et al., 2010) ou Santos-SP (PIVELLI, 2016). O uso difundido de poucas espécies na arborização urbana foi considerado normal por Silva (2003). Todavia, apenas Poincianella pluviosa (31,9\%) excedeu a recomendação de Grey e Deneke (1986), segundo os quais a abundância de cada espécie não deve exceder mais que 15\%, porque a abundância de uma única espécie ocasionaria maior risco de ocorrência de pragas e fitopatologias.

Em relação à origem das espécies identificadas neste inventário, 22 espécies foram classificadas como exóticas $(68,8 \%)$ e nove como nativas $(28,1 \%)$, além de uma espécie não classificada $(3,1 \%)$. Considerando a quantidade de indivíduos, 68 exemplares $(58,6 \%)$ pertencem às espécies nativas e $47(40,5 \%)$ às espécies exóticas. No diagnóstico das praças de Aracaju - SE, Souza et al. (2011) constataram a maior proporção de espécies exóticas (58\%) em relação às nativas (42\%). Sousa et al. (2014) apresentaram resultado contrário ao 
estudo supracitado e a presente pesquisa, após avaliarem a arborização de uma praça em São Paulo - SP (exóticas: 30,6\% do total de espécies). De acordo com Sousa et al. (2014), é recomendável utilizar espécies nativas, preferencialmente nativas regionais, para o possível estabelecimento de corredores ecológicos. Além da interação com a fauna e flora regional, as espécies nativas implantadas no ambiente urbano podem ser utilizadas em atividades de educação ambiental, evidenciando, por exemplo, a necessidade de conservação de espécies ameaçadas de extinção e as funções que as árvores podem exercer no ambiente natural.

Tabela 1. Número de indivíduos e origem das espécies amostradas em praças da cidade de Guaçuí - ES Table 1. Individuals number and species origin sampled in the Guaçuí-ES squares

\begin{tabular}{|c|c|c|c|c|c|}
\hline Família & Nome Científico & Nome popular & $\mathbf{n}$ & $\%$ & Origem \\
\hline \multirow[t]{10}{*}{ Arecaceae } & Caryota urens L. & $\begin{array}{l}\text { palmeira-rabo-de- } \\
\text { peixe }\end{array}$ & 1 & 0,86 & Exótica \\
\hline & Cocos nucifera L. & coqueiro & 1 & 0,86 & Exótica \\
\hline & Dypsis lutescens (H. Wendl.) Beentje \& J. Dransf. & areca-bambu & 10 & 8,62 & Exótica \\
\hline & Euterpe edulis Mart. & palmiteiro-juçara & 2 & 1,72 & Nativa \\
\hline & Livistona chinensis (Jacq.) R. Br. ex Mart. & falsa-latânia & 1 & 0,86 & Exótica \\
\hline & Phoenix roebelenii O'Brien & $\begin{array}{l}\text { tamareira-de- } \\
\text { jardim }\end{array}$ & 2 & 1,72 & Exótica \\
\hline & Roystonea borinquena O.F. Cook & $\begin{array}{l}\text { palmeira-coca- } \\
\text { cola }\end{array}$ & 5 & 4,31 & Exótica \\
\hline & Roystonea regia (Kunth) O.F. Cook & palmeira-real & 2 & 1,72 & Exótica \\
\hline & Syagrus romanzoffiana (Cham.) Glassman & jerivá & 5 & 4,31 & Nativa \\
\hline & ${ }^{*}$ Roystonea sp. & palmeira & 1 & 0,86 & Exótica \\
\hline \multirow[t]{2}{*}{ Asparagaceae } & Dracaena fragrans (L.) Ker Gawl. & $\begin{array}{l}\text { coqueiro-de- } \\
\text { vênus }\end{array}$ & 3 & 2,59 & Exótica \\
\hline & Yucca guatemalensis Baker & iuca-elefante & 1 & 0,86 & Exótica \\
\hline \multirow[t]{3}{*}{ Bignoniaceae } & Handroanthus chrysotrichus (Mart. ex DC.) Mattos & sipê-amarelo & 1 & 0,86 & Nativa \\
\hline & Handroanthus pentaphyllus (L.) Mattos & ipê-rosa & 2 & 1,72 & Exótica \\
\hline & Jacaranda mimosifolia D. Don & jacarandá & 3 & 2,59 & Exótica \\
\hline \multicolumn{2}{|c|}{ Chrysobalanaceae Licania tomentosa (Benth.) Fritsch } & oiti & \multicolumn{2}{|c|}{1512,93} & Nativa \\
\hline Cupressaceae & Cupressus sempervirens L. & cipreste-italiano & 2 & 1,72 & Exótica \\
\hline Cycadaceae & Cycas thouarsii R. Br. & cica & 1 & 0,86 & Exótica \\
\hline \multirow[t]{7}{*}{ Fabaceae } & Bauhinia forficata Link & pata-de-vaca & 2 & 1,72 & Nativa \\
\hline & Bauhinia variegata $\mathrm{L}$. & pata-de-vaca & 1 & 0,86 & Exótica \\
\hline & & flamboiã & 1 & 0,86 & Exótica \\
\hline & Paubrasilia echinata (Lam.) E. Gagnon, H.C. Lima & apau-brasil & 3 & 2,59 & Nativa \\
\hline & Peltophorum dubium (Spreng.) Taub. & canafístula & \multirow{2}{*}{\multicolumn{2}{|c|}{$\begin{array}{cc}2 & 1,72 \\
37 & 31,90\end{array}$}} & Nativa \\
\hline & Poincianella pluviosa (DC.) L.P.Queiroz & sibipiruna & & & Nativa \\
\hline & Tipuana tipu (Benth.) Kuntze & tipuana & 2 & 1,72 & Exótica \\
\hline Lauraceae & Cinnamomum camphora (L.) J. Presl & canforeira & 1 & 0,86 & Exótica \\
\hline Moraceae & Ficus benjamina L. & figueira-benjamina & 3 & 2,59 & Exótica \\
\hline $\begin{array}{l}\text { Muntingiaceae } \\
\text { Myrtaceae }\end{array}$ & cf. Muntingia sp. & calabura & 1 & 0,86 & Exótica \\
\hline \multirow{2}{*}{$\begin{array}{l}\text { Myrtaceae } \\
\text { Nvctaainaceae }\end{array}$} & Syzygium jambos (L.) Alston & jambo & 1 & 0,86 & Exótica \\
\hline & Bougainvillea glabra Choisy & primavera & 1 & & Nativa \\
\hline \multirow{2}{*}{$\begin{array}{l}\text { Proteaceae } \\
\text { Rutaceae }\end{array}$} & Grevillea robusta A. Cunn. ex R. Br. & grevílea & 1 & 0,86 & Exótica \\
\hline & Murraya paniculata (L.) Jack & murta & 1 & \multirow{2}{*}{$\begin{array}{l}0,86 \\
0,86\end{array}$} & Exótica \\
\hline \multirow[t]{2}{*}{-} & Indeterminada & - & 1 & & - \\
\hline & \multicolumn{2}{|l|}{ Total } & \multicolumn{2}{|c|}{116100} & - \\
\hline
\end{tabular}


Quanto às condições gerais da arborização urbana, verificou-se que a maior parte das árvores tinha uma condição fitossanitária boa (86,2\%), contrastando com a baixa proporção de árvores em estado fitossanitário ruim (6,9\%). Nenhuma árvore morta foi observada nas quatro áreas pesquisadas. Entre as áreas públicas, somente as praças da Matriz e Vicente Camuzi não continham árvores com problemas fitossanitários visíveis, enquanto foi constatada a necessidade de manejo fitossanitário em determinada proporção das árvores da praça João Acacinho e da área da Prefeitura. Estes resultados indicam que a arborização das áreas públicas pesquisadas, em Guaçuí - ES, teve melhor condição fitossanitária quando comparada às praças pesquisadas por Redin et al. (2010) em Cachoeira do Sul - RS (62,6\% das árvores) e Tischer, Forte e Pedroso-de-Moraes (2014) em Leme - SP (56\% das árvores), onde as proporções de árvores em boa condição sanitária foram inferiores (Tabela 2).

Tabela 2. Características qualitativas da arborização de áreas verdes públicas da cidade de Guaçuí - ES Table 2. Qualitative characteristics of the public afforestation of Guaçuí - ES

\begin{tabular}{|c|c|c|c|c|c|}
\hline \multirow[b]{2}{*}{ Variáveis } & \multicolumn{4}{|c|}{ Área verde pública } & \multirow[b]{2}{*}{ Geral } \\
\hline & $\begin{array}{c}\text { P. João } \\
\text { Acacinho }\end{array}$ & P. Matriz & $\begin{array}{l}\text { P. Vicente } \\
\text { Camuzi }\end{array}$ & Prefeitura & \\
\hline Número de árvores & 49 & 23 & 14 & 30 & 116 \\
\hline \multicolumn{6}{|l|}{ Fitossanidade (\%) } \\
\hline Boa & 79,6 & 100,0 & 100,0 & 80,0 & 86,2 \\
\hline Regular & 14,3 & 0,0 & 0,0 & 3,3 & 6,9 \\
\hline Ruim & 6,1 & 0,0 & 0,0 & 16,7 & 6,9 \\
\hline Total & 100,0 & 100,0 & 100,0 & 100,0 & 100,0 \\
\hline \multicolumn{6}{|l|}{ Sistema radicular (\%) } \\
\hline Profundo e sem danos & 87,8 & 95,7 & 64,3 & 76,7 & 83,6 \\
\hline Superficial e sem danos & 6,1 & 4,3 & 35,7 & 3,3 & 8,6 \\
\hline Danos moderados & 6,1 & 0,0 & 0,0 & 16,7 & 6,9 \\
\hline Danos severos & 0,0 & 0,0 & 0,0 & 3,3 & 0,9 \\
\hline $\begin{array}{r}\text { Total } \\
\end{array}$ & 100,0 & 100,0 & 100,0 & 100,0 & 100,0 \\
\hline \multicolumn{6}{|l|}{ Qualidade da copa (\%) } \\
\hline Boa & 79,6 & 95,7 & 100,0 & 83,3 & 86,2 \\
\hline Regular & 8,2 & 4,3 & 0,0 & 13,3 & 7,8 \\
\hline Ruim & 12,2 & 0,0 & 0,0 & 3,3 & 6,0 \\
\hline Total & 100,0 & 100,0 & 100,0 & 100,0 & 100,0 \\
\hline \multicolumn{6}{|l|}{ Necessidade de poda (\%) } \\
\hline Não apresenta & 79,6 & 100,0 & 42,9 & 83,3 & 80,2 \\
\hline Limpeza & 2,0 & 0,0 & 7,1 & 6,7 & 3,4 \\
\hline Afastamento & 16,3 & 0,0 & 21,4 & 6,7 & 11,2 \\
\hline Liberação de fiação & 2,0 & 0,0 & 28,6 & 3,3 & 5,2 \\
\hline Total & 100,0 & 100,0 & 100,0 & 100,0 & 100,0 \\
\hline
\end{tabular}

O sistema radicular de $92,2 \%$ das árvores foi profundo ( $83,6 \%$ do total) ou superficial ( $8,6 \%$ do total) em canteiros e não causou danos aos pisos de passeios e ruas, bem como a outros equipamentos urbanos. Danos moderados (poucas rachaduras ou leve elevação no piso) causados pelo sistema radicular foram observados na Praça João Acacinho (6,1\%) e na área circundante à Prefeitura (16,7\%), sendo a maior proporção de problemas observados na 
área da Prefeitura, onde $20 \%$ das árvores causou danos moderados ou severos. Esta condição pode ser atribuída ao plantio inadequado de espécies, evidente, por exemplo, pelo tamanho reduzido da área livre ao redor do fuste das árvores plantadas nas calçadas, condição observada in loco. Tal aspecto é corroborado por Santos e Teixeira (2001), segundo os quais a área livre insuficiente resulta no mau desenvolvimento das árvores. Segundo estes autores, a área livre é o espaço sem pavimento que permite a infiltração de água e nutrientes. A partir dessa definição, podemos considerar que uma área livre é suficiente onde permita uma boa infiltração de água e nutrientes no solo. Nesse contexto, notou-se que um plantio inadequado, que dificulta o crescimento do sistema radicular, possivelmente ocasionou problemas fitossanitários nas árvores urbanas. Tal característica foi exposta na presente pesquisa, em que apenas as áreas com conflitos entre o sistema radicular e elementos urbanos construídos tiveram árvores com estado fitossanitário ruim. Acrescenta-se que podas inadequadas também podem ter afetado a fitossanidade das árvores.

A qualidade da copa das árvores, de forma geral, foi boa $(86,2 \%)$, sendo que apenas $6,0 \%$ da arborização das quatro áreas analisadas teve qualidade de copa ruim. A praça Vicente Camuzi e a praça da Matriz continham apenas árvores com copa de qualidade boa ou regular. Por outro lado, a Praça João Acacinho teve destaque por conter a maior proporção de árvores com qualidade de copa ruim (12,2\%). As condições ruins das copas das árvores podem diminuir o potencial estético e funcional da arborização como um todo, minimizando benefícios aos seres humanos como o sombreamento.

Em relação à necessidade de poda, $80,2 \%$ dos indivíduos registrados não necessitavam de podas, por conseguinte, 19,8\% requeriam algum tipo de poda. Entre as quatro áreas, apenas a praça da Matriz não teve árvores que demandavam alguma intervenção, evidenciando que esta área pública teve planejamento e manejo adequado de arborização urbana. Em contraste, na Praça Vicente Camuzi, a necessidade de poda foi verificada em $57,1 \%$ das árvores, onde também foi constatada a maior demanda por podas para a liberação de fiação elétrica $(28,6 \%)$ e o afastamento de construções $(21,4 \%)$. A poda de limpeza foi demandada por uma baixa proporção de árvores $(3,4 \%)$, sendo maior na Praça Vicente Camuzi $(7,1 \%)$ e na área da Prefeitura (6,7\%). Esses resultados indicam a existência de níveis de planejamento ou manutenção antagônicos na arborização urbana de Guaçuí.

A área total amostrada foi de $7731 \mathrm{~m}^{2}$, correspondente as quatro áreas de dimensões entre 900 a $2600 \mathrm{~m}^{2}$ aproximadamente. Em três áreas verdes públicas, a área sombreada pelas copas das árvores foi superior à dimensão da respectiva avaliada (Tabela 3). Entre essas, a Praça João Acacinho teve o maior índice de sombreamento arbóreo (ISA=154,7\%), enquanto a Praça da Matriz teve o menor ISA (59,8\%). Lima Neto, Resende e Souza (2007) indicaram que o ISA recomendado para áreas comerciais é de 30\% e para áreas residenciais é 
de 50\%, a partir do seu estudo realizado nas praças de Aracaju - SE. Assim sendo, infere-se que as quatro áreas públicas pesquisadas em Guaçuí - ES possuem índices de sombreamento acima do recomendado.

Tabela 3. Índices de sombreamento da arborização de áreas verdes públicas da cidade de Guaçuí - ES Table 3. Shading indices of afforestation in public areas of Guaçuí - ES

\begin{tabular}{lccccc}
\hline \multicolumn{1}{c}{ Área pública } & $\begin{array}{c}\text { Área total } \\
\left(\mathbf{m}^{\mathbf{2}}\right)\end{array}$ & $\begin{array}{c}\text { Área sombreada } \\
\left(\mathbf{m}^{2}\right)\end{array}$ & $\mathbf{N I}$ & $\begin{array}{c}\text { ISA } \\
(\%)\end{array}$ & $\begin{array}{c}\text { IDA } \\
(\text { árvores/100m }\end{array}$ \\
\hline Praça João Acacinho & 2488,00 & 3849,19 & 49 & 154,7 & 1,97 \\
Praça Matriz & 2603,00 & 1557,26 & 23 & 59,8 & 0,88 \\
Praça Vicente Camuzi & 920,00 & 1041,28 & 14 & 113,2 & 1,52 \\
Prefeitura & 1720,00 & 1825,66 & 30 & 106,1 & 1,74 \\
\hline
\end{tabular}

NI: número de indivíduos; ISA: índice de sombreamento arbóreo; IDA: índice de densidade arbórea.

O índice de densidade arbórea (IDA) calculado para as quatro áreas públicas variou de 0,88 a 1,97, sendo o menor valor encontrado na Praça da Matriz e o maior valor na Praça João Acacinho, respectivamente. Esses resultados são em geral superiores aos obtidos por Lima Neto e Souza (2009) para áreas verdes públicas de Aracaju - SE, onde o IDA variou de 0,16 a 1,18. Entretanto, o recomendável é que as áreas tenham pelo menos 7 a 10 árvores/100 m² (LIMA NETO; RESENDE; SOUZA, 2007; LIMA NETO; SOUZA, 2009), evidenciando que as áreas públicas avaliadas em Guaçuí - ES têm carência de vegetação arbórea.

Analisando-se a área de projeção das copas das espécies com três ou mais indivíduos, foi constatado que Poincianella pluviosa $\left(119,24 \mathrm{~m}^{2}\right)$, Jacaranda mimosifolia D. Don $\left(73,03 \mathrm{~m}^{2}\right)$ e Licania tomentosa $\left(57,07 \mathrm{~m}^{2}\right)$ tiveram as maiores médias na área de copa, em contraste com as espécies Dracaena fragans (L.) Ker Gawl. (6,26 $\left.\mathrm{m}^{2}\right)$ e Dypsis lutescens (8,51 $\mathrm{m}^{2}$ ) (Figura 2).

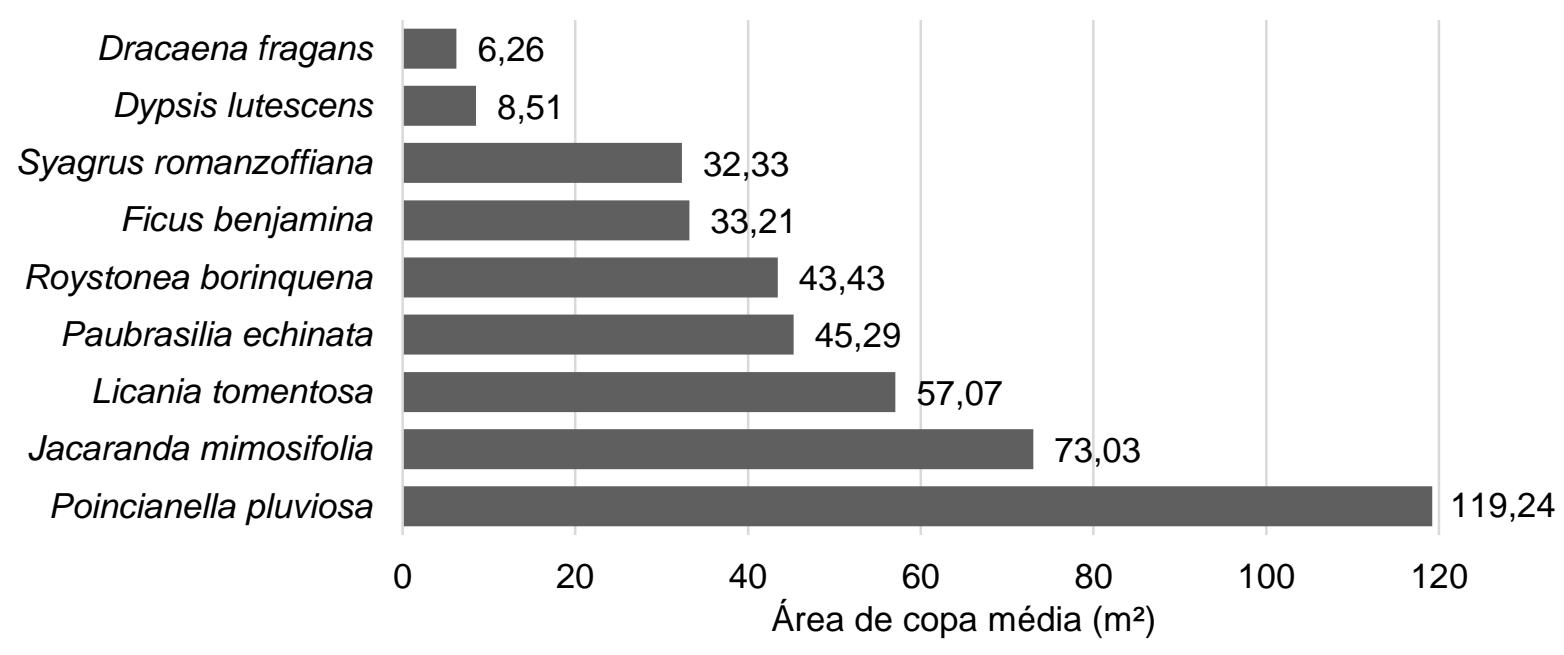

Figura 2. Área de copa média das espécies com três ou mais indivíduos amostrados arborização de áreas verdes públicas da cidade de Guaçuí - ES

Figure 2. Average crown area sampled in the species with three or more individuals used in public afforestation of Guaçuí - ES 
Tais resultados evidenciam o elevado potencial de uso de P. pluviosa, J. mimosifolia e L. tomentosa para obtenção de sombra em áreas verdes. Acrescenta-se que P. pluviosa e J. mimosifolia também têm floração com elevado valor ornamental, o que aumenta o seu potencial de uso na arborização urbana, por expressarem ao longo do ano qualidade estética (floração chamativa) e funcional (sombreamento).

\section{CONCLUSÕES}

As famílias botânicas Arecaceae e Fabaceae tiveram respectivamente o maior número de espécies e de indivíduos utilizados na arborização das quatro áreas públicas avaliadas. $A$ presença de maior número de espécies exóticas (22) em detrimento do baixo número de espécies nativas (nove), indica a necessidade de valorização e implantação de mais espécies nativas, preferencialmente da região.

As quatro áreas apresentam potenciais de sombreamento satisfatórios (superiores a 50\%), apesar de terem densidade arbórea inferiores à recomendação (7 a 10 árvores/100 m²). Entre as espécies analisadas, Poincianella pluviosa $\left(119,24 \mathrm{~m}^{2}\right)$ e Jacaranda mimosifolia $\left(73,03 \mathrm{~m}^{2}\right)$ tiveram as maiores áreas de copa média, destacando-se como espécies de elevado potencial de sombreamento.

Com base nas características qualitativas avaliadas, foi diagnosticado que a vegetação nas áreas de estudos estava com boas condições gerais, apesar de demandar algumas práticas manejo como podas e tratamento fitossanitário. A praça Vicente Camuzi teve a maior demanda por poda, principalmente de afastamento de construções e para liberação de fiação conflituosa com a copa das árvores.

\section{REFERÊNCIAS}

ALVARES, C. A.; STAPE, J. L.; SENTELHAS, P. C., GONÇALVES, J. L. M.; SPAROVEK, G. Köppen's climate classification map for Brazil. Meteorologische Zeitschrift, Stuttgart, v. 22, n. 6, p. 1-18, 2013.

ALVES; J. de A.; CARVALHO, D. A. de. A família Arecaceae (palmeiras) no município de Lavras, MG. Cerne, Lavras, v. 16, n. 2, p. 163-170, 2010.

BORTOLETO, S.; SILVA FILHO, D. F. da; SOUZA, V. C.; FERREIRA, M. A. de P.; POLIZEL, J. L.; RIBEIRO, R. de C. S. Composição e distribuição da arborização viária da estância de Águas de São Pedro-SP. Revista da Sociedade Brasileira de Arborização Urbana, Piracicaba, v. 2, n. 3, p. 32-46, 2007. 
BYNG, J. W.; CHASE, M. W.; CHRISTENHUSZ, M. J. M.; FAY, M. F.; JUDD, W. S.; MABBERLEY, D. J.; SENNIKOV, A. N.; SOLTIS, D. E.; SOLTIS, P. S.; STEVENS, P. F. An update of the Angiosperm Phylogeny Group classification for the orders and families of flowering plants: APG IV. Botanical Journal of the Linnean Society, London, v. 181, n. 1, p. 1-20, 2016.

FARIA, D. G.; DUARTE, J. M. de A.; PINTO, D. M.; ALMEIDA, F. S. Arborização urbana no município de Três Rios - RJ: espécies utilizadas e a percepção de seus benefícios pela população. Revista da Sociedade Brasileira de Arborização Urbana, Piracicaba, v. 8, n. 2, p. 58-67, 2013.

FLORES, T. B.; ALVARES, C. A.; SOUZA, V. C.; STAPE, J. L. Eucalyptus no Brasil zoneamento climático e guia para identificação: aptidão por município. Disponível em: $<$ http://www.ipef.br/publicacoes/guiaeucalyptus/aptidao.aspx>.

FORZZA, R. C.; COSTA, A. F.; WALTER, B. M. T.; BICUDO, C.; MOURA, C. W. N.; PERALTA, D. F.; COSTA, D. P. da; BARROS, F. de; LIMA, H. C. de; PRADO, J.; STEHMANN, J. R.; BAUMGRATZ, J. F. A.; PIRANI, J. R.; SYLVESTRE, L. das; MAIA, L. C.; LOHMANN, L. G.; PAGANUCCI, L.; NADRUZ, M.; MAMEDE, M. C. H.; SOARES, M. de L.; BARBOSA, M. R.; MENEZES, M.; MORIM, M. P.; ROQUE, N.; EVANGELISTA, P. H. L.; VIANA, P. L.; GOLDENBERG, R.; SECCO, R.; RODRIGUES, R. S.; CAVALCANTI, T. B.; MANSANO, V. Flora do Brasil 2020. Disponível em: <http://www.floradobrasil.jbrj.gov.br>. Acesso em: 17 fev. 2017.

GREY, G. W.; DENEKE, F. J. Urban forestry. New York: John Wiley \& Sons, 1986. 279p.

INSTITUTO BRASILEIRO DE GEOGRAFIA E ESTATISTICA (IBGE). Cidades. Disponível em: <http://cod.ibge.gov.br/C1O> Acesso em: 17 fev. 2017.

LIMA NETO, E. M. de; RESENDE, W. J.; SOUZA, E. M. Áreas verdes púbicas do centro de Aracaju - SE: análise fitogeográfica. Revista da Fapese, Aracaju, v. 3, n. 2, p. 5-16, 2007.

LIMA NETO, E. M. de; SOUZA, E. M. Índices de densidade e sombreamento arbóreo em áreas verdes públicas de Aracaju, Sergipe. Revista da Sociedade Brasileira de Arborização Urbana, Piracicaba, v. 4, n. 4, p. 47-62, 2009.

MARANHO, A. S.; PAULA, S. R. P. de. Diversidade em uma área verde urbana: avaliação qualitativa da arborização do campus da Universidade Federal do Acre, Brasil. Revista Agro@mbiente, Boa Vista, v. 8, n. 3, p. 404-415, 2014.

MISSOURI BOTANICAL GARDEN (MBG). Tropicos ${ }^{\circledR}$. Disponível em: <http://www.tropicos.org >. Acesso em: 17 fev. 2017.

OLIVEIRA, L. M. de; SANTOS, A. F. dos; SOUZA, P. A. de; ALVES, K. C. C. de L. F.; GIONGO, M. Diagnóstico da arborização nas calçadas de Gurupi, TO. Revista da Sociedade Brasileira de Arborização Urbana, Piracicaba, v. 12, n. 1, p. 105-121, 2017.

PIRES, N. A. M. T.; MELO, M. da S.; OLIVEIRA, D. E. de; XAVIER-SANTOS, S. A arborização urbana do município de Goiandira/GO - caracterização quali-quantitativa e propostas de manejo. Revista da Sociedade Brasileira de Arborização Urbana, Piracicaba, v. 5, n. 3, p. 185-205, 2010. 
PIVELLI, S. R. P. Inventário quantitativo e mapeamento das espécies de porte arbóreo do Orquidário Municipal - Parque Zoobotânico, Santos-SP. UNISANTA Bioscience, Santos, v. 5, n. 4, p. 369-381, 2016.

REDIN, C. G.; VOGEL, C.; TROJAHN, C. D. P.; GRACIOLI, C. R.; LONGHI, S. J. Análise da arborização urbana em cinco praças do município de Cachoeira do Sul, RS. Revista da Sociedade Brasileira de Arborização Urbana, Piracicaba, v. 5, n. 3, p. 149-164, 2010.

SANTOS, N. R. Z.; TEIXEIRA, I. F. Arborização de vias públicas: ambiente x vegetação. Santa Cruz do Sul: Instituto Souza Cruz, 2001. 135p.

SCHALLENBERGER, L. S.; ARAUJO, A. J. de; ARAUJO, M. N. de; DEINER, L. J.; MACHADO, G. de $O$. Avaliação da condição de árvores urbanas nos principais parques e praças do município de Irati - PR. Revista da Sociedade Brasileira de Arborização Urbana, Piracicaba, v. 5, n. 2, p. 105-123, 2010.

SILVA, A. G. Inventário de arborização urbana viária: métodos de amostragem, tamanho e forma de parcelas. Viçosa, 2003. 124f. Tese (Doutorado em Ciências Florestais) - Programa de Pós-Graduação em Ciência Florestal da Universidade Federal de Viçosa, Viçosa, 2003.

SOUSA, R. de C.; AGUIAR, O. T. de; SILVA, L. T. A. da; SILVA, L. A.; MARRA, R. C. Avaliação quali-quantitativa da arborização na praça Agostinho Nohama, bairro Lauzane Paulista, São Paulo - SP. Revista da Sociedade Brasileira de Arborização Urbana, Piracicaba, v. 9, n. 1, p. 92-107, 2014.

SOUZA, A. L. de; FERREIRA, R. A.; MELLO, A. A. de; PLÁCIDO; D. da R.; SANTOS, C. Z. A. dos; GRAÇA, D. A. S. da; ALMEIDA JÚNIOR, P. P. de; BARRETTO, S. S. B.; DANTAS, J. D. de M.; PAULA, J. W. A. de; SILVA, T. L. da; GOMES, L. P. S. Diagnóstico quantitativo e qualitativo da arborização das praças de Aracaju, SE. Revista Árvore, Viçosa, v. 35, n. 6, p. 1253-1263, 2011.

TEIXEIRA, I. F.; FIGUEIREDO, F. M.; TABORDA, I. G. R.; SOARES, L. M. Análise fitossociológica da praça Camilo Mércio no centro histórico de São Gabriel, RS. Revista da Sociedade Brasileira de Arborização Urbana, Piracicaba, v. 11, n. 1, p. 1-13, 2016.

TISCHER, J. C.; FORTE, A. R.; PEDROSO-DE-MORAES, C. Análise qualiquantitativa de indivíduos arbóreos das praças centrais do município de Leme, SP. Revista da Sociedade Brasileira de Arborização Urbana, Piracicaba, v. 9, n. 3, p. 49-64, 2014. 